\title{
Invasive Squamous Carcinoma of the Vulva in Young Patients
}

\author{
Yew Cheong Choo, M.D. \\ Division of Gynecologic Oncology, Department of Obstetrics and Gynecology, \\ University of Michigan Hospital, Ann Arbor, Michigan 48109
}

Received April 16, 1981

\begin{abstract}
Over a 30-year period, 17 patients below the age of 35 with invasive squamous carcinoma of the vulva were identified, 8 of whom (47.1\%) had "microinvasive" disease. Venereal diseases and condyloma accuminata were not predisposing factors. Immunosuppression was a contributory factor in 2 patients. Although carcinoma in situ was antecedent in only 1 patient, it was an associated lesion in $87.5 \%$ of patients with "microinvasive" and $22.2 \%$ of patients with invasive carcinoma. The nature and course of this disease in young patients do not differ from the elder counterpart. Prolonged follow-up of these patients has revealed increased susceptibility of the perineum, vagina, and cervix to multiple neoplasms.
\end{abstract}

\section{INTRODUCTION}

Invasive squamous carcinoma of the vulva is a disease classically afflicting the aged beyond the fifth and sixth decade who are often obese, hypertensive, and diabetic [1,2]. Reports of larger series of cases pointed to the paucity of patients below the age of $35[1,3,4]$; the youngest patient documented was 14 [5]. Earlier reports also suggested that venereal diseases could be predisposing factors in invasive vulvar carcinoma in patients who are younger than the average age [6-8]. In addition, patients with condyloma accuminata of the vulva [9-11], or those immunosuppressed $[12,13]$ may also develop invasive vulvar carcinoma at a younger age.

Lately, carcinoma in situ of the vulva appears to be on the rise in young females $[11,14,15]$. Biologically and histopathologically, vulvar carcinoma is said to be dissimilar to carcinoma of the cervix [16]; this implication, and whether the in-situ carcinoma has any bearing on the invasive counterpart, is uncertain. Increasing attention has also been focused on the so-called early, superficially invasive, or "microinvasive" vulvar carcinoma [17-19]. The question of a continuum from in situ disease and the question of metastasis are also uncertain.

Regardless of the above, invasive carcinoma of the vulva when found in the young is a serious disease. The surgical treatment is mutilating, and its emotional and psychological repercussions are immense. This has prompted considerations of less radical operations in selected young patients who have early invasive carcinoma [18]. This study was undertaken to determine whether any predisposing factors or associated conditions exist in young patients with invasive 
carcinoma and whether its course of events is different from that of the older age group.

\section{MATERIALS AND METHODS}

From January 1950 through December 1979, 515 patients with a malignancy of the vulva were seen at the University of Michigan Hospital. Sixty-three patients were below the age of 35, and the youngest was 18. Forty-two of them had carcinoma in situ and the remaining 21 had the following malignancies: invasive squamous carcinoma-17, malignant melanoma-2, leiomyosarcoma1 , and Bartholin gland carcinoma-1. The 17 patients with invasive squamous vulvar carcinoma were analyzed in detail with regard to age and parity, presentation, associated conditions, treatment, and follow-up status. The pathological slides were reviewed, noting also the areas adjacent to the lesion. Staging of the disease was made according to the current criteria of the International Federation of Gynaecology and Obstetrics [20]. Early invasion or "microinvasion" was defined as invasion beyond the basal layer of the epidermis of not more than $5 \mathrm{~mm}$ in depth from the surface of the lesion, with or without an overlying epithelium. Survivors following radical vulvectomy were interviewed to evaluate their psychological sequelae following surgery. They were asked about their comprehension of the surgery, the impact of the surgery on their bodily image and sexual rehabilitation, and the attitudes of their sexual partner.

\section{RESULTS}

The age of the patients ranged from 23 to 35 (mean, 28 years). Parity ranged from 0 to 8 (average, 3.2). The most common symptom was pruritus, present in 8 patients, and 2 patients were asymptomatic. The lesion was described as a tumor in 10 , ulcer in 5 , and leukoplakia in 2 . In 4 patients with a growth, a white lesion adjacent to the growth was also seen. One patient was originally diagnosed as having lichen sclerosus et atrophicus for 4 months until a growth was discovered. In 1 other patient, the growth had the appearance of lymphogranuloma vencreum, but a Frei test was inconclusive. Obesity and hypertension were not found, but 1 patient had diabetes of juvenile onset, and she also had Fanconi's syndrome as well as proven immunodeficiency as a result of repeated episodes of pulmonary infections. One patient had Hodgkin's disease, treated initially with irradiation and subsequently with chemotherapy for recurrent disease. A history of vulvar carcinoma in situ prior to invasive carcinoma was elicited in one patient with a 6-year interim period. With respect to the onset of symptoms to diagnosis, patient delay was found to average 10 months, while physician delay in diagnosis averaged 16 months, for in many of these patients cancer was not suspected at all.

The treatment modalities in both the early invasive and invasive carcinoma are as shown in Table 1. Age was always a consideration in the decision on individual treatment; this was more so in recent years. The conventional radical vulvectomy and groin lymphadenectomy was employed in 3 of 8 patients with early invasive, and 8 of 9 patients with frank invasive carcinoma. Among those with invasive carcinoma, 6 had Stage I, 2 Stage II, and 1 Stage III disease. One 
TABLE 1

Treatment Modalities in Patients with Early Invasive and Frank Invasive Carcinoma of THE VULVA

\begin{tabular}{lcc}
\hline & $\begin{array}{c}\text { Early } \\
\text { invasive carcinoma }\end{array}$ & Invasive carcinoma \\
\hline RV, GLND & 3 & 7 \\
RV, GLND, PLND & - & 1 \\
TV, GLND & - & 1 \\
Wide excision, GLND & 1 & - \\
Subtotal vulvectomy & 3 & - \\
No treatment & 1 & - \\
Total & 8 & 9 \\
\hline
\end{tabular}

${ }^{a} \mathrm{RV}$, radical vulvectomy; TV, total vulvectomy; GLND, groin lymph node dissection; PLND, pelvic lymph node dissection.

patient with an invasive carcinoma less than $2 \mathrm{~cm}$ in size was treated with only a total vulvectomy and groin lymphadenectomy. In patients with early invasive disease, it was noted that 3 had subtotal vulvectomy alone, and 1 had a wide excision of the vulvar lesion with bilateral groin lymphadenectomy. One patient with early invasive discase had her treatment withheld in view of advanced Hodgkin's disease.

The associated pathological findings are as shown in Table 2. Carcinoma in situ was found at the margin of the lesion in 7 of 8 patients $(87.5 \%)$ with early invasive carcinoma and 2 of 9 patients (22.2\%) with invasive carcinoma. Three of nine patients $(33.3 \%)$ with invasive carcinoma had surrounding lichen sclerosis, but without associated atypia or hyperplasia.

Follow-up of these patients has revealed that 7 had developed a recurrence or a new primary carcinoma many years after treatment. The sites included urethral meatus, vagina, cervix gluteal skin, and perineum (Table 3).

In patients who had early invasive carcinoma, 4 deaths occurred from nonrelated causes, this includes the patient who had Hodgkin's disease. The remaining 4 patients are alive with no evidence of disease from 1 to 17 years. Of the patients with invasive carcinoma, one death occurred in a 28-year-old patient who had a Stage III undifferentiated carcinoma with metastasis to the pelvic nodes. Despite surgery and pelvic irradiation, she died 8 months later. Three other patients also died, all without disease and more than 10 years following treatment. Four patients are presently alive without disease from 4 to 22 years.

TABLE 2

Associated Pathology at the Margin of Lesions

\begin{tabular}{lccc}
\hline & No. & $\begin{array}{c}\text { Associated with } \\
\text { lichen sclerosis }\end{array}$ & $\begin{array}{c}\text { Associated with } \\
\text { CIS }\end{array}$ \\
\hline $\begin{array}{l}\text { Early invasive Ca } \\
\text { Frank invasive Ca }\end{array}$ & 8 & - & $7(87.5 \%)$ \\
\hline
\end{tabular}


TABLE 3

Type and Intfruat. of Nfw Lesions following Treatment of Vulva Ca in Seven Patients

\begin{tabular}{|c|c|c|c|}
\hline $\begin{array}{l}\text { Vulvar } \mathrm{Ca}- \\
\text { early invasive }\end{array}$ & $\begin{array}{l}\text { Interval } \\
\text { (years) }\end{array}$ & $\begin{array}{l}\text { Vulvar } \mathrm{Ca}- \\
\text { invasive }\end{array}$ & $\begin{array}{c}\text { Interval } \\
\text { (years) }\end{array}$ \\
\hline CIS gluteal skin & 4 & CIS perineum & 12 \\
\hline \multirow{4}{*}{$\begin{array}{l}\text { Invasive squamous Ca } \\
\text { urethral meatus }\end{array}$} & & CIS perineum & 17 \\
\hline & 9 & Invasive $\mathrm{Ca}$ vagina & 8 \\
\hline & & $\begin{array}{l}\text { Invasive squamous } \mathrm{Ca} \\
\text { cervix }\end{array}$ & 20 \\
\hline & & $\begin{array}{l}\text { Invasive squamous } \mathrm{Ca} \\
\text { urethral meatus }\end{array}$ & 8 \\
\hline
\end{tabular}

Six patients were interviewed on their thoughts regarding radical vulvectomy. All appeared to have sufficient understanding of the surgery initially. Five patients expressed some regrets about the surgery, realizing though the intent was cure of their disease. One thought that surgery to rid her of the unbearable pruritus was the most important reason for undergoing the surgery. All, however, wished that surgery could be less disfiguring. When compared with mastectomy, radical vulvectomy appeared to be less traumatic to their bodily image. Readjustment following surgery was not difficult in the majority of patients. One patient took more than a year to accept surgical ablation of her external genitalia. Another patient, even 8 years after surgery, has persistent suicidal thoughts requiring regular psychiatric consultations and treatment. In terms of sexual functions, all but one patient reported no significant decrease in libido. As regard orgasmic feeling during sexual intercourse, three reported no difference; two had diminished sensation, and in one patient, it was absent. Surgery had no effect on the sexual attitudes of their partner. One patient did complain of difficult intercourse as a result of introital stenosis, but a suggested vaginoplasty was refused by the patient concerned. None of the six patients interviewed had any significant bladder or bowel dysfunction following surgery.

\section{DISCUSSION}

Invasive squamous carcinoma of the vulva is a rare disease in young patients below the age of 35 , and comprised only $3.3 \%$ of patients with malignancies of the vulva seen at the University of Michigan Hospital over a 30-year period. Its occurrence in young patients must, however, be recognized, for the preinvasive as well as the early invasive carcinoma are being seen more frequently in young patients.

Venereal disease was found not to be a predisposing factor in this group of patients, contrary to older reports [6-8], although in one patient, lymphogranuloma venereum could not definitely be excluded.

Lichen sclerosis was found to be a significant associated lesion in three of nine patients $(33.3 \%)$ with invasive carcinoma but not in patients with early invasive carcinoma. In these patients, no hyperplasia or atypia was found to imply a 
cause-effect relationship. In general, lichen sclerosis is said to be an associated lesion in 3 to $4 \%$ of patients with invasive squamous vulvar carcinoma $[16,19,21]$. It is unusual for lichen sclerosis to progress to invasive carcinoma unless hyperplasia and atypia occurred. Hart [21] reported only 1 case in an analysis of 107 patients with lichen sclerosus et atrophicus. Conversely, it is more usual for the vulvar dystrophy of the hyperplastic type to be associated with invasive vulvar carcinoma $[16,22]$.

It is tempting, in vulvar carcinoma, to postulate a continuum of the neoplastic process from in situ carcinoma through microinvasion to frank invasion. Such a sequence of events has not been proven on definite grounds. Friedrich [23] reported 5 cases out of 50 patients with carcinoma in situ progressing to invasion; Buscema [13] also reported 5 such patients, and a case each was reported by Tovell [24] and Jones [25]. In this series of patients, only 1 patient had carcinoma in situ antecedent to an early invasive carcinoma. Immunosuppression has been suggested to be a predisposing cause for carcinoma in situ of the vulva progressing to invasive disease in young patients [13]. This relationship, if true, is present in one of our patients, and possibly in another who was probably immunosuppressed as a result of treatment for Hodgkin's disease.

It is a significant finding that $88.9 \%$ of the early invasive and $22.2 \%$ of the overt invasive vulvar carcinoma had associated carcinoma in situ. The carcinoma in situ bordering frank invasive vulvar carcinoma was often abrupt, while that associated with early invasion was often extensive, merging with the focus or foci of microinvasion. In general, it is said that carcinoma in situ occurs at the margins of invasive vulvar carcinoma in approximately $20 \%$ of cases $[16,19]$. The high incidence of concomitant carcinoma in situ in early invasive vulvar carcinoma is striking. Barnes [26] suggested that there are two types of microinvasive vulvar carcinoma: one is associated with extensive overlying carcinoma in situ, and the other is seldom associated with in situ disease but tends to metastasize.

Young patients with invasive vulvar carcinoma do not appear to have a more advanced disease when first diagnosed or to have a different course of the disease compared to their elderly counterparts. In this series of patients, none of those who had early invasive carcinoma died of her disease, and in those who had groin lymphadenectomy, no lymph node metastasis was detected. In patients with invasive carcinoma, only one death was recorded attributable to progressive disease.

The young age of these patients when their disease was first diagnosed made study of their long term follow-up possible. Seven of seventeen patients $(41.2 \%)$ had developed a new lesion in the lower genital region 4 to 20 years after initial treatment. In many of these patients, the new lesion appears to be new primary lesion rather than recurrence of the original vulvar carcinoma. One must be aware that the new perineum after vulvectomy, the cervix and the vagina are all potential sites for the development of multiprimary neoplasms [27].

The treatment of young patients with invasive vulvar carcinoma should take into consideration their age and the potential mental trauma. The postvulvectomy syndrome may persist for a long interval and may even lead to suicidal inclination in the extreme as exemplified by one such patient. These patients should rightly 
be subjected to extensive counseling before surgery. In addition, a sympathetic and compassionate approach with constant reassurances are all essential elements toward rehabilitating these patients. A less radical approach is recommended in treating young patients with early invasive carcinoma if the lesion is less than $2 \mathrm{~cm}$, without evidence of total anaplasia or vascular permeation [17]. An even more conservative approach as advocated by Di Saia [18], consisting of sampling the superficial inguinal nodes and performing a wide excision of the vulvar lesion only if the frozen section of the lymph nodes are negative, may also be considered in selected patients.

\section{REFERENCES}

1. Green, T. H., Ulfelder, H., and Meigs, J. V. Epidermoid carcinoma of the vulva: An analysis of 238 cases. Part 1. Etiology and diagnosis, Amer. J. Obstet. Gynecol. 75, 834-847 (1958).

2. Franklin, E. W., and Rutledge, F. D. Epidemiology of epidermoid carcinoma of the vulva, Obstet. Gynecol. 39, 165-172 (1972).

3. Taussig, F. J. Cancer of the vulva, Amer. J. Obstet. Gynecol. 40, 764-779 (1972).

4. Collins, C. G., Collins, J. H., Barclay, D. L., and Nelson, E. W. Cancer involving the vulva. A report on 109 consecutive cases, Amer. J. Obstet. Gynecol. 87, 762-772 (1963).

5. Lister, U. M., and Akinla, O. Carcinoma of the vulva in childhood, J. Obstet. Gynecol. Brit. Commonw. 79, 470-473 (1972).

6. Lunin, A. Carcinoma of the vulva. A review of fifty cases, Amer. J. Obstet. Gynecol. 57, 742-747 (1949).

7. Salzstein, S. C., Woodruff, J. D., and Novak, E. R. Post-granulomatous carcinoma of the vulva, Obstet. Gynecol. 7, 80-90 (1956).

8. Hay, D. M., and Cole, F. M. Primary invasive carcinoma of the vulva in Jamaica, J. Obstet. Gynaecol. Brit. Commonw. 76, 821-830 (1969).

9. Rhatigan, S. M., and Saffos, R. D. Condyloma accuminata and squamous carcinoma of the vulva, South. Med. J. 70, 591-594 (1977).

10. Woodruff, J. D., and Novak, E. R. Premalignant lesions of the vulva, Clin. Obstet. Gynecol. 5, 1102-1118 (1962).

11. Kovi, J., Tillman, R. L., and Lee, S. M. Malignant transformation of condyloma accuminata, Amer. J. Clin. Palhol. 61, 702-710 (1974).

12. Friedrich, E. G., Wilkinson, E. J., and Fu, Y. S. Carcinoma in situ of the vulva. A continuing challenge, Amer. J. Obstet. Gynecol. 136, 830-843 (1980).

13. Buscema, J., and Woodruff, J. D. Progressive histological alterations in the development of vulva cancer. Report of 5 cases, Amer. J. Obstet. Gynecol. 138, 146-150 (1980).

14. Woodruff, J. D., Julian, C., Puray, T., Mermut, S., and Katayama, P. The contemporary challenge of carcinoma in situ of vulva, Amer. J. Ohstet. Gynerol. 115, 677-686 (1973).

15. Japaze, H., Garcia-Bunnell, R., and Woodruff, J. D. Primary vulvar carcinoma. A review of in situ and invasive carcinoma, 1935-1972, Obstet. Gynecol. 49, 404-411 (1977).

16. Buscema, J., Stern, J., and Woodruff, J. D. The significance of the histologic alterations adjacent to invasive vulvar carcinoma, Amer. J. Obstet. Gynecol. 137, 902-909 (1980).

17. Parker, R. T., Duncan, I., Rampone, J., and Creasman, W. Operative management of early invasive epidermoid carcinoma of the vulva, Amer. J. Obstet. Gynecol. 123, 349-355 (1975).

18. Di Saia, P. J., Creasman, W. T., and Rich, W. M. An alternate approach to early cancer of the vulva, Amer. J. Obstet. Gynecol. 133, 825-832 (1979).

19. Magrina, J. F., Webb, M. J., Gaffey, T. A., and Symmonds, R. E. Stage I squamous cell cancer of the vulva, Amer. J. Obstet. Gynecol. 134, 453-459 (1979).

20. Classification and staging of malignant tumours in the female pelvis, Acta Obstet. Gynecol. Scand. 50, 1-8 (1971).

21. Hart, W. R., Nurris, H. J., and Helwig, E. B. Relationship of lichen sclerosis et atrophicus of the vulva to the development of carcinoma, Obstet. Gynecol. 15, 369-377 (1975).

22. Kaufman, R. H. Hyperplastic dystrophy, J. Reprod. Med. 17, 137-145 (1976). 
23. Friedrich, E. G. discussion of paper by Buscema, J., Stern, J., and Woodruff, J. D. The significance of the histologic alterations adjacent to invasive vulvar carcinoma, Amer.J. Obstet. Gynecol. 137, 908 (1980).

24. Tovell, H. M. M. Discussion of paper by Friedrich, E. G., Wilkinson, E. J., and Fu, Y. S. Carcinoma in situ of the vulva. A continuing challenge, Amer. J. Obstet. Gynecol. 136, 840 (1980).

25. Jones, L., and Buntine, D. Progression of vulval carcinoma in situ, Aust. N.Z.J. Obstet. Gynaecol. 18, 274-276 (1968).

26. Barnes, A. E., Crissman, J. D., Schellhas, H. F., and Azoury, R. S. Microinvasive carcinoma of the vulva, a clinicopathological evaluation, Obstet. Gynecol. 56, 234-238 (1980).

27. Choo, Y. C., and Morley, G. W. Multiple primary neoplasms of the anogenital region, Obstet. Gynecol. 56, 365-369 (1980). 